\title{
MUTAGENIC SENSITIVITY OF SPERM, SPERMATIDS, SPERMATOCYTES AND SPERMATOGONIA IN DROSO- PHILA MELANOGASTER
}

\author{
A. C. CHANDLEY and A. J. BATEMAN \\ Christie Hospital and Holt Radium Institute, Manchester

\section{INTRODUCTION} \\ Received 26.vii.6o
}

LÜNING (1952a), measuring dominant lethal incidence in successive days' matings following a single dose of X-rays in Drosophila melanogaster, found a variation in sensitivity in post-meiotic stages, which he confirmed by his work with hyperploids (1952b). This variation was attributed to hypersensitivity of the early post-meiotic stages, that is, spermatids. Auerbach (1954), using three-day "brood" periods and testing for recessive autosomal and sex-linked lethals found a peak mutational response in the second brood i.e. 4-7 days after irradiation (which she equated to spermatids at irradiation). This was followed by a period of high sterility in the third brood.

This hypersensitivity of spermatids has now been established in D. melanogaster for dominant lethals (Lüning, I952a, Bateman, I956); hyperploids (Lüning, I952b, Bateman, 1957); autosomal and sexlinked lethals (Auerbach, I 954, Oster, I955, I956.); and translocations (Oster, 1955, 1956); and also in $D$. virilis for dominant lethals and translocations (Alexander and Stone, 1955).

In the "brood pattern" technique of Auerbach (1954) where each brood is the product of three days' matings, the mutation rates measured will represent average effects in what may often be heterogeneous material. Furthermore, the contribution of each day's mating to a brood will be weighted according to its fertility which itself will be expected to vary systematically, and thus a bias will be introduced into the overall brood result.

In the present study, it was desired to determine whether the changes in sensitivity were the same for different sectors of the mutation spectrum. For this purpose, dominant lethals, deleted X's, and translocations (all structural changes), autosomal and sex-linked lethals (mainly gene changes) were followed in the same material. At the same time evidence of induced crossing-over in the $b \mathrm{pr} v g$ region of chromosome II was obtained, primarily for its value in identifying spermatogenic stages, though it proved to have a value in its own right.

It would have been cumbersome to follow daily changes in all these mutations, so four days were selected as being most representative. The second day after irradiation of the male showed the minimum sensitivity of sperm to dominant lethals. The eighth day had shown 
the maximum sensitivity for deleted X's and was the last day for high dominant lethal rate. The eleventh day showed a return to control values for deleted X's and dominant lethals and almost certainly represented spermatogonia surviving irradiation. The fifth day was chosen as this was half-way in time between the second and eighth.

\section{MATERIALS AND METHODS}

The males which were used throughout the experiment were the $F_{1}$ hybrid between Birmingham Outbred females and $b$ pr vg males.

For each run, $25 F_{1}$ males which had emerged overnight were irradiated in the morning with Iooor X-rays (a Resomax X-ray tube run at $300 \mathrm{kV}$ was used for all exposures). Immediately after treatment they were mated to $F_{1}$ females at the rate of two per male per day. This mating rate was used throughout the course of the experiment and was chosen in order to ensure that sperm was used as it matured and was not stored (Bateman, 1956) a situation which would lead to the mixing of successive batches of sperm and confuse the sensitivity pattern of the several spermatogenic stages.

On day 2, which was the first sampling day, the males were divided into five equal groups A-E, the five males in each group being allocated to a different type of female in the ratio of two females to each male.

Group A males were mated to Muller-5 females for the detection of sex-linked recessive lethals.

Group B males were mated to $\frac{C y L}{P m}, \frac{H}{S b}$ stock females for the estimation of autosomal recessive lethals and translocations. Group $\mathrm{G}$ males were back-crossed to $b$ pr vg females in order to detect induced crossing-over.

Group $\mathrm{D}$ males were mated to $\mathrm{F}_{1}$ females and the rate of dominant lethals was scored as the percentage non-hatching eggs (using the technique of Bateman, 1956). The dominant lethal rate was used to check that each batch of males was conforming to the usual pattern in sensitivity and rate of spermatogenesis. An unirradiated control series was run concurrently.

In Group E, the males were mated to $y v f$ car attached-X females for the determination of deleted X's, which were recognised in the progeny as non-yellow (i.e. hyperploid) daughters.

This procedure was repeated on each of the other sampling days, 5, 8 and II. Sometimes, during the periods between the main sampling days, the males were mated to $b$ prvg females instead of $F_{1}$ females in order to follow the incidence of induced crossing-over. In this way, the daily frequency of crossing-over was obtained from day 2 up to and including day 13.

Successive runs of the experiment were made until sufficient data had been obtained for our purposes.

In estimating standard errors for some of the mutation rates we have followed the advice of Stevens (1942) in allowing for the skewness of probability distributions at low frequencies. Instead of the conventional \pm symbol for the standard error we have quoted separately the upper and lower limits at the probability level of $0 \cdot 15$, which is the level corresponding to the standard error.

\section{RESULTS}

\section{(i) Dominant lethals}

Table I shows the percentages of unhatched eggs on the four sampling days for control and treated males. From this the reader can judge the consistency of the ten successive runs. The overall mean percentages are also given with their standard errors based upon 
variation between runs. Fig. I $a$ shows the variation in dominant lethal rate graphically for both irradiated males and unirradiated controls, with the results of Bateman (1956) for comparison. The incidence of dominant lethals rises sharply from day 2 to day 5 and rises further to a peak on day 8 . This second rise could be spurious,

TABLE I

Percentage of non-hatching eggs following I ooor $X$-rays to males

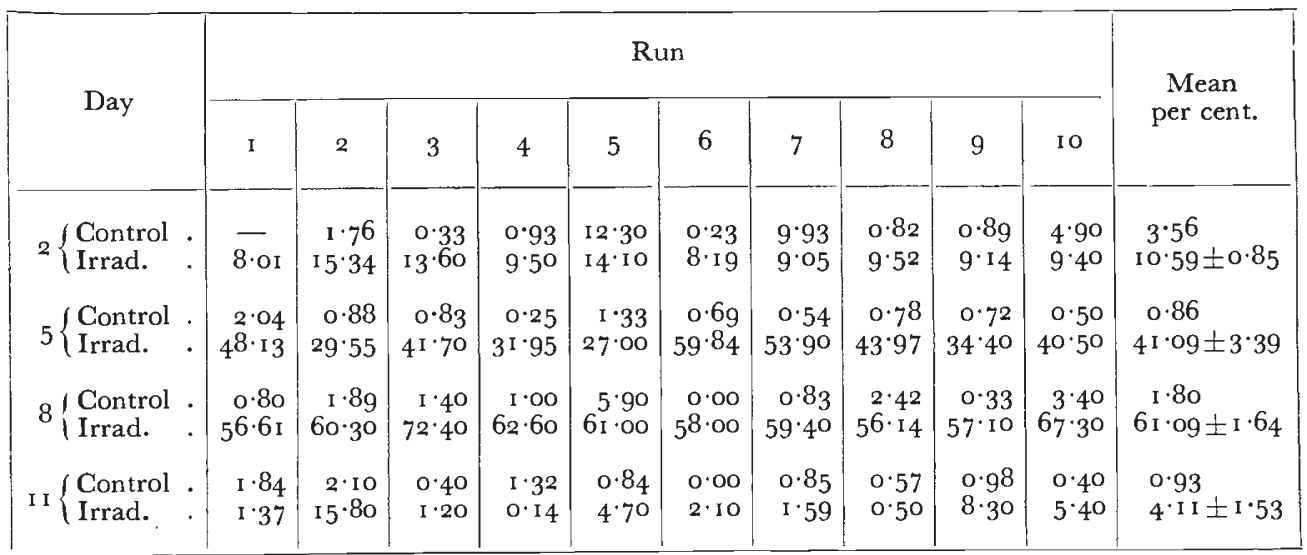

however, if the non-hatching percentages contained a large number of unfertilised eggs. Day i I shows a drop to a value just slightly higher than the control level.

As stated previously, the dominant lethal incidence was followed mainly as a check on the running conditions of the experiment, but also fully confirms earlier observations.

\section{(ii) Deleted X's}

Table 2 gives the hyperploid frequency obtained over the four sampling days following Iooor X-rays. These data, though not very

TABLE 2

Percentage Hyperploidy following Iooor $X$-rays to males

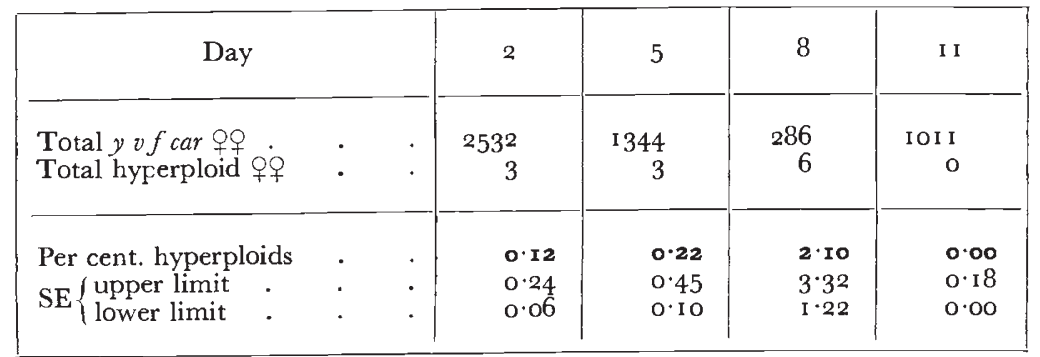

extensive, fully confirm the peak incidence at day 8 found earlier (Bateman, I957). The results are expressed graphically in fig. I $b$. 

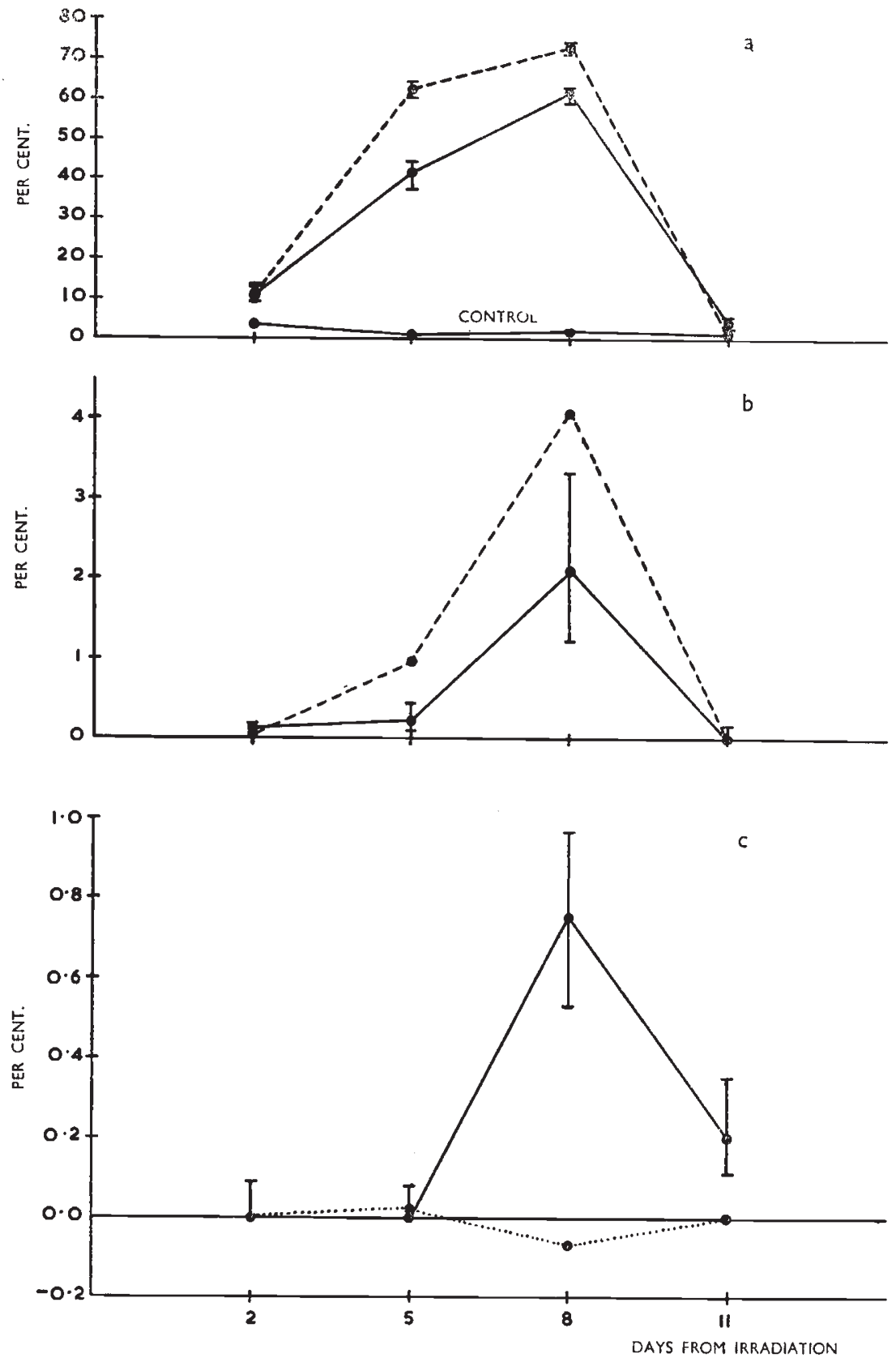

Fig. 1.-Variation in the rate of $(a)$ Dominant lethals, $(b)$ Hyperploids and $(c)$ Cross-overs and "Mutations" on days 2, 5, 8 and I I following 1 ooor X-rays. In graphs $(a)$ and (b) continuous lines represent present data. Broken lines represent data of Bateman (1956, 1957). In graph $(c)$ continuous line represents per cent. cross-overs and dotted line represents per cent. "mutation" from present data.

Standard errors are represented by vertical lines. 
(iii) Autosomal recessive lethals

The data on the frequency of recessive autosomal lethals are given in table 3 and fig. $2 a$.

The highest mutation rate was found on day 5 (I2.19 per cent.). On day 8 , the day showing the highest rate of both dominant lethals and deleted X's, the level of autosomal lethals was definitely lower ( 7.95 per cent.), indeed half-way between the values for day 5 and day I I, (3.82 per cent.) which showed a mutation rate even lower than day 2 (5. I 2 per cent.).

Analysis of the data obtained on the four days showed a highly significant variation between days. The standard errors were calculated

TABLE 3

Percentage autosomal and sex-linked recessive lethals following rooor $X$-rays to males

\begin{tabular}{|c|c|c|c|c|c|}
\hline Day & & 2 & 5 & 8 & I I \\
\hline $\begin{array}{l}\text { Autosomals } \\
\text { Total } \\
\text { Lethal . } \\
\text { Per cent. lethal }\end{array}$ & : & $\begin{array}{c}78 \mathrm{I} \\
40 \\
5 \cdot 12 \pm 0 \cdot 79\end{array}$ & $\begin{array}{c}607 \\
74 \\
\mathrm{I} 2 \cdot \mathrm{I} 9 \pm \mathrm{I} \cdot 33\end{array}$ & $\begin{array}{c}566 \\
45 \\
7 \cdot 95 \pm \mathrm{I} \cdot \mathrm{I} 4\end{array}$ & $\begin{array}{c}680 \\
26 \\
3 \cdot 82 \pm 0 \cdot 74\end{array}$ \\
\hline $\begin{array}{l}\text { Sex-linked } \\
\text { Total } \\
\text { Lethal . } \\
\text { Per cent. lethal }\end{array}$ & : & $\begin{array}{c}944 \\
19 \\
2 \cdot 01 \pm 0 \cdot 46\end{array}$ & $\begin{array}{c}617 \\
35 \\
5 \cdot 67 \pm 0 \cdot 93\end{array}$ & $\begin{array}{c}44^{\circ} \\
15 \\
3.4^{1} \pm 0.87\end{array}$ & $\begin{array}{c}73 \mathrm{I} \\
9 \\
\mathrm{I} \cdot 23 \pm 0 \cdot 4 \mathrm{I}\end{array}$ \\
\hline $\begin{array}{l}\text { Ratio autosomal/ } \\
\text { sex-linked }\end{array}$ & • & $2 \cdot 5$ & $2 \cdot I$ & $2 \cdot 3$ & $3 \cdot 1$ \\
\hline
\end{tabular}

from the total sample sizes on each day assuming homogeneity between successive runs of the experiment.

The results are in agreement with those of Auerbach (I954) who found a significant increase in mutation rate following 2ooor X-rays, in the second brood, that is matings 4-7 days after treatment. In the tests for autosomal lethals however, Auerbach found excessive sterility in the treated males in the second brood. This she attributed to a speeding up of the rate of sperm release by the use of $C y L$ females, so that treated spermatocytes were already being utilised in the second brood. In all our matings, however, this period of sterility was confined to the single day 8 . The difference may be due to the different dose levels (2000 and ıoor respectively).

\section{(iv) Sex-linked lethals}

The frequency of sex-linked recessive lethals is shown in table 3 and fig. $2 b$. There is a striking parallelism with the variation in autosomal lethal incidence. Statistical analysis of the results showed a highly significant variation between days with no detectable heterogeneity 
between runs. The standard errors were based on the total sample sizes for each day. The reduced yield of sex-linked lethals from later matings of irradiated males has generally (e.g. Auerbach, 1954, Khishin,
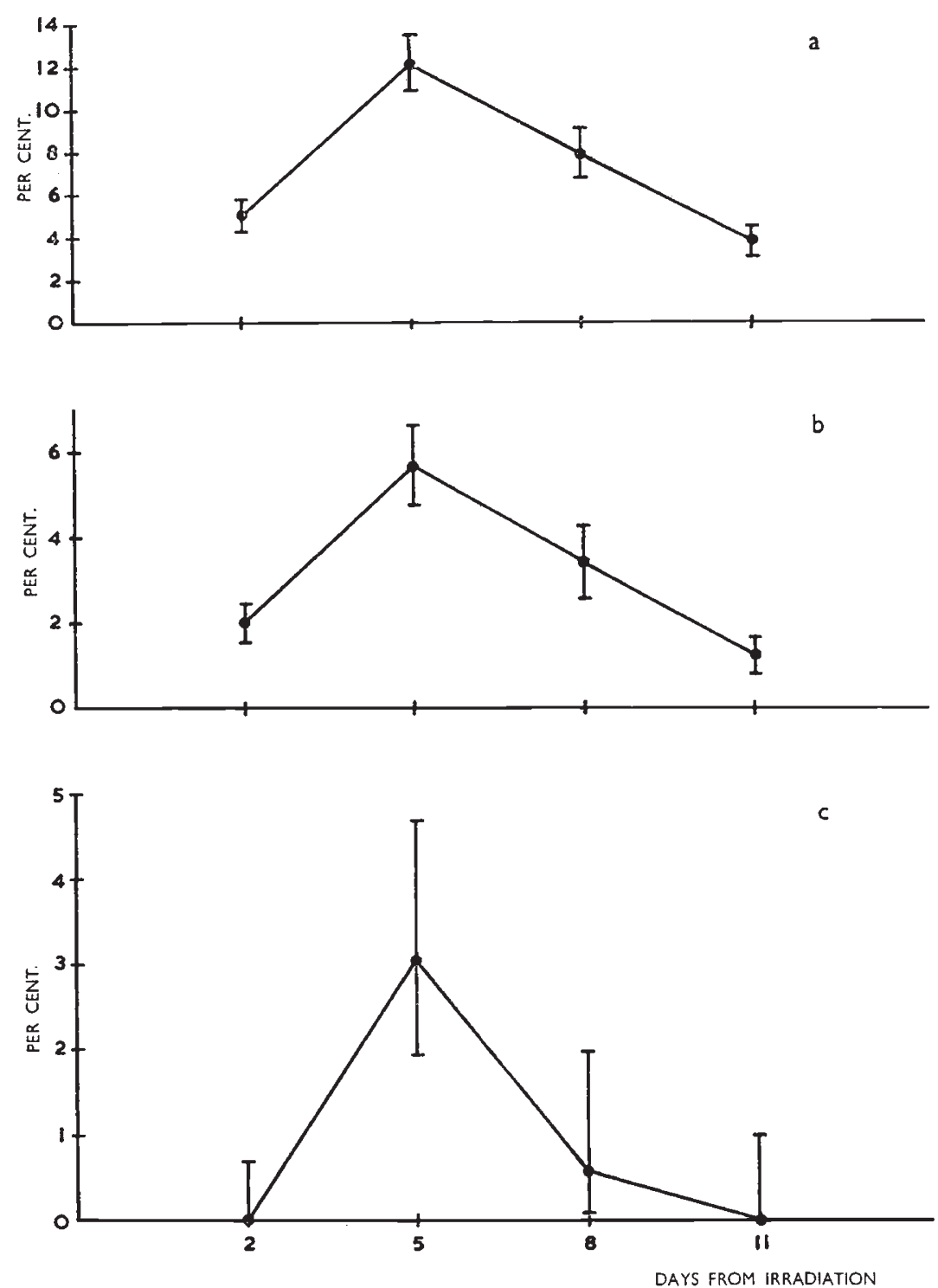

Fig. 2.- Variation in the rate of (a) Recessive autosomal lethals (b) Recessive sex-linked lethals and (c) Translocations on days 2, 5, 8 and I f following rooor X-rays.

Standard errors are represented by vertical lines.

I955) been attributed to germinal selection eliminating spermatogonia hemizygous for lethals. The dose similarity, however, between the results obtained for autosomal and sex-linked recessive lethals on all the sampling days, and emphasised by the ratio of mutation rates shown 
in the bottom row of table 3 , suggests that germinal selection cannot be the main factor. This must be reduced sensitivity of spermatogonia to the induction of mutations. There is, however, a suggestion that the ratio of autosomal to sex-linked lethals is higher on day I than previously, so some germinal selection may be operative. It is also possible that germinal selection would have been more marked in matings later than day I I. It is clear, however, that the main cause of reduction in yield of mutations from day 5 to day I I and also the less spectacular reduction from day 2 to day I I is due to variation in sensitivity to the mutagen, affecting autosomal and sex-linked lethals to similar extents.

\section{(v) Translocations}

Table 4 and fig. $2 c$ show the translocations recovered on the four sampling days following Iooor. Although very few translocations

TABLE 4

Percentage translocations following rooor $X$-rays to males

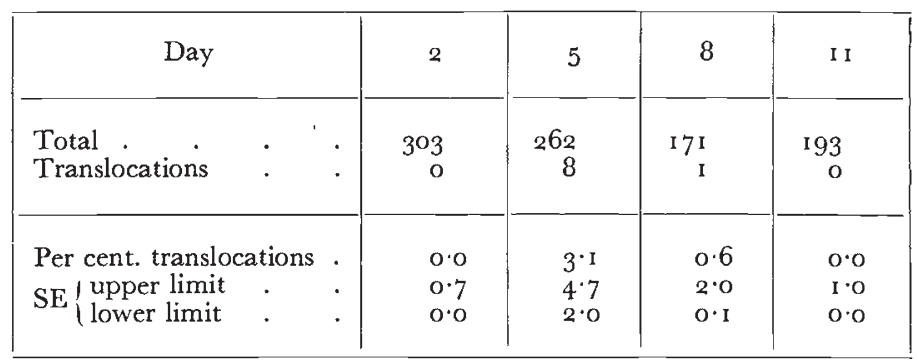

were recovered the results indicate a greater sensitivity for day 5 than any other day. These data are, therefore, consistent with the recessive lethal data rather than with the other structural changes (dominant lethals and deleted X's).

\section{(vi) Induced crossing-over}

Estimates of the rate of induced crossing-over were made over days 2-I3. The results obtained are set out in table 5 and fig. I $c$ and fig. 3. The intention was to provide a means of identifying the specific stages of germ cell development at irradiation corresponding to each day's mating. As crossing-over can only occur in diploid cells, any cross-overs induced will indicate spermatogonia or spermatocytes at irradiation.

The map distances based on crossing-over in the female are $b$-pr 6.o units, pr-vg 12.5 units. In the analysis of cross-over data using three markers, Auerbach (1954) has distinguished two cross-over classes: animals showing a single recessive marker $\left(r_{1}\right)$ and those showing two recessives $\left(r_{2}\right)$. Each $r_{2}$ phenotype has a complementary $r_{1}$ phenotype which should be produced by crossing-over with 

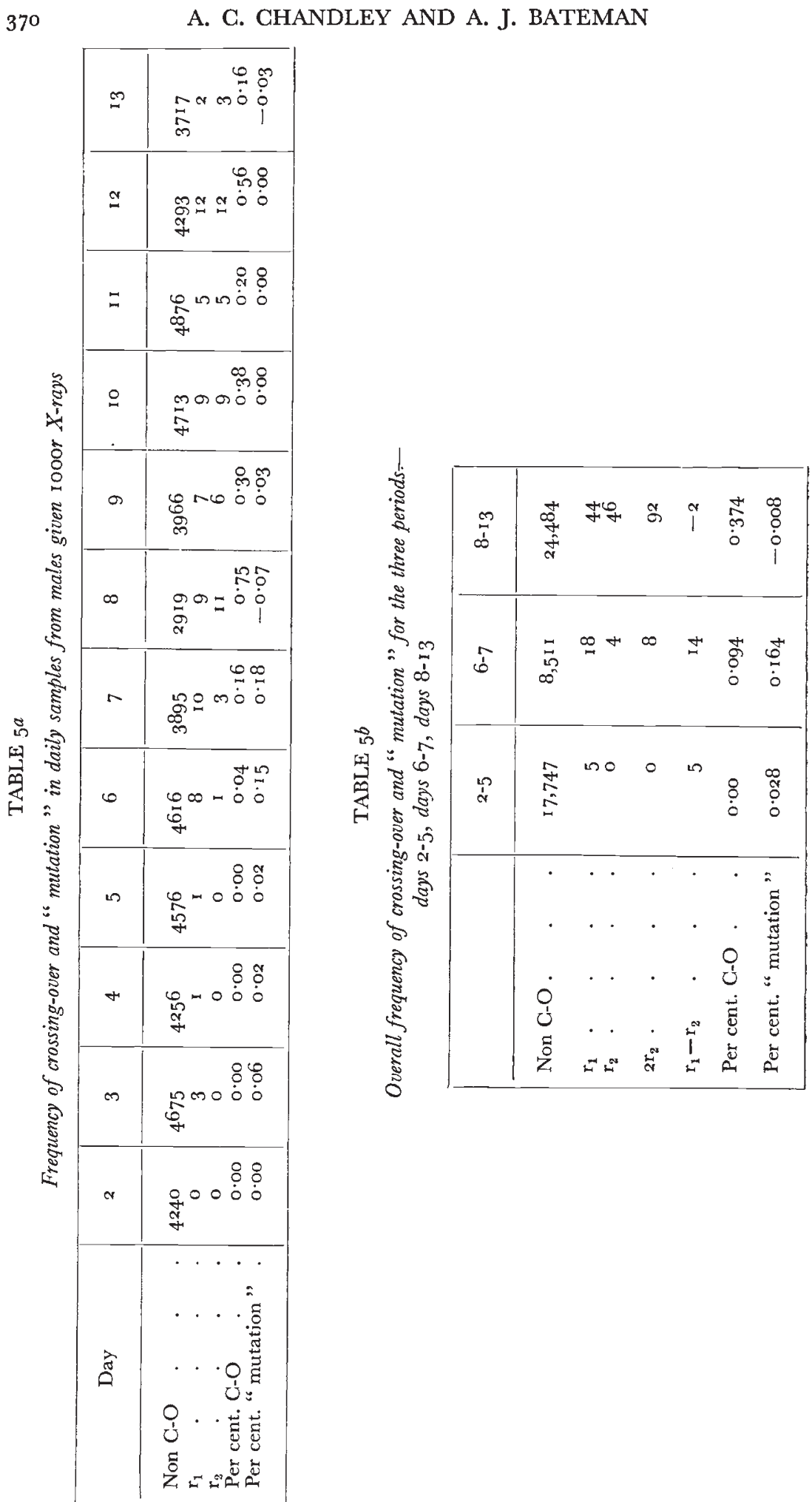
equal frequency. When, therefore, there is an excess of $r_{1}$ over $r_{2}$ one must suspect causes other than true crossing-over. Apart from crossing-over, $\mathrm{r}_{2}$ can only be produced by back-mutation at the third locus or deletions large enough to include two loci. On the other hand, $\mathrm{r}_{1}$ can be produced not only by mutation at that locus (including lethal mutations) but also by small deletions. It follows that $r_{2}$ can be taken as a much more reliable estimate of crossing-over than $r_{1}$. In the table, therefore, the " cross-overs" have been used to estimate two parameters: $2 r_{2}$ or the true cross-overs, and $\left(r_{1}-r_{2}\right)$, the mutations and deletions collectively referred to as "mutations". The results of this analysis are shown in fig. 3. For comparison with the other data, fig. I $c$ shows the values on days $2,5,8$ and I I only.

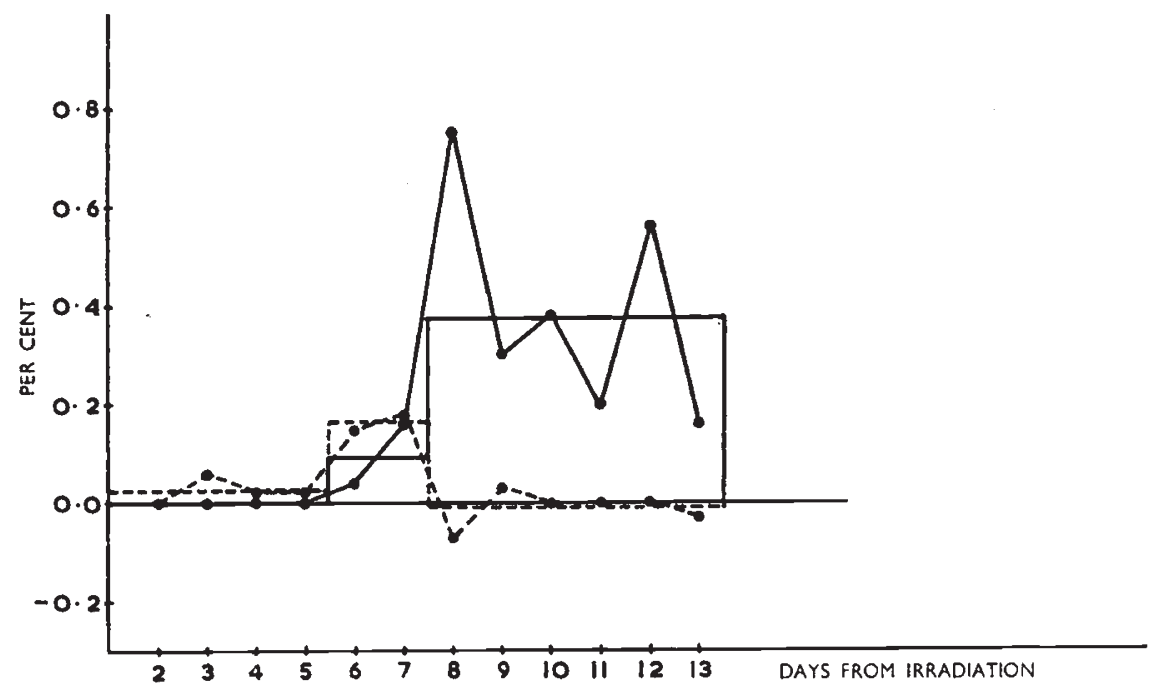

FIG. 3.-Variation in the rate of cross-overs and "mutations" in daily samples following rooor X-rays. Continuous line equals per cent. cross-overs $\left(2 r_{2}\right)$. Broken line equals per cent. "mutations" $\left(r_{1}-r_{2}\right)$. Histograms show the mean level for cross-overs (continuous line) and "mutations" (broken line) over the three periods, days 2-5, 6-7 and 8-13.

The whole period surveyed can be divided into three qualitatively different stages: days 2-5 showing no crossing-over and a low level of "mutations"; days 6 and 7 showing a low level of crossing-over but the highest rate of " mutations" encountered, and days 8-13 during which crossing-over rises to a maximum and deletions are not evident.

Assuming that crossing-over can only occur in diploid cells it seems that days 2-5 represent irradiated sperm and spermatids, days 6-7 spermatocytes, and days 8-13 spermatogonia. The high sensitivity of spermatogonia to the induction of crossing-over is well established (Friesen, 1937, Auerbach, 1954, Sobels and van Steenis, I957).

The reaction of spermatocytes as such does not appear to have been previously recorded. This stage, in which crossing-over is induced much less readily than in spermatogonia seems particularly susceptible, however, to the induction of small deletions. 
Further evidence that many of the $r_{1}$ class are not cross-overs is shown by a more detailed analysis. By crossing-over in heterozygotes for $b \mathrm{pr} v g$, $p r$ animals must be double cross-overs. These would be an extremely rare class, considering the infrequency of even single crossovers. In all, there were io $p r$ flies and none of the reciprocal class $b v g$. They occurred in spermatids, spermatocytes and spermatogonia and must represent either mutations or deletions. Out of the total of Ioo genuine cross-overs $\left(2 \mathrm{r}_{2}\right), 90$ occurred in the segment $p r-v g$ and only Io in the segment $b-p r$. Of the putative deletions $\left(\mathrm{r}_{1}-\mathrm{r}_{2}\right)$ the loci $b$ and $p r$ had Io each, but $v g$ had none (estimated as -3 ).

In fig. 3 there is a suggestion of alternately high and low values for crossing over from day 8 onwards. A $\chi^{2}$ test for heterogeneity on this part of the data, gave a value of $2 \mathrm{I} \cdot 4 \mathrm{O}$ for 5 degrees of freedom, which has a probability of o.0oI. The biggest contribution to this was $7 \cdot 99$ for day 8, which may represent a special category of germ cell, either just before or just after the last spermatogonial mitosis. In view of the fact that this is the day showing the greatest reduction in fertility after irradiation, there might be one cell stage which is completely eliminated and the mutations observed are from stages on either or both sides of it. In the latter case stages with contrasting sensitivities might be occurring in the same day's sample. Or again, the sperm tested may be from the few survivors of the stage which is most readily sterilised by X-rays. By analogy with the mouse (Oakberg, i955) this would be the last generation of spermatogonia.

On removing day 8 there is still considerable heterogeneity $\left(\chi_{(4)}^{2}=13.98\right)$ with a probability of o.or. Perhaps this reflects the variation in sensitivity during each successive mitotic cycle.

\section{DISCUSSION}

The attempt to find other categories of mutation which would repeat the sensitivity pattern of either dominant lethals or deleted $\mathrm{X}$ 's has evidently failed. On the other hand, sex-linked lethals, autosomal lethals and translocations show closely similar sensitivity patterns. This is especially so if one assumes that translocations, being proportional to a power of the dose greater than unity, would increase more rapidly than recessive lethals with increasing sensitivity of the cell stage.

The sensitivity pattern for dominant lethals up to day 8 could be reconciled with that for these other mutations if one assumed that a high proportion of unhatched eggs from day 8 matings were in fact unfertilised eggs owing to acute shortage of sperm. There is certainly a much lower rate of egg laying on that day (see Bateman, 1956) in a stock where virgin females lay only an occasional egg, so one can assume there is in fact a shortage of sperm. It remains to be established that the egg laying rate is imperfectly adjusted to the amount of sperm available so that when sperm is scarce the fertilisation rate is lowered- 
or alternatively that egg laying is proportional to the total sperm, which on day 8 includes a high proportion lacking the capacity for fertilisation.*

In comparing the sensitivity patterns for various types of mutation, allowance must be made for the fact that chromosome rearrangements of whatever kind are never recovered from irradiated spermatogonia. This applies to dominant lethals (e.g. Bateman, I956), deleted X's (Bateman, 1957), translocations and inversions (Ward and Alexander, 1957). In the case of translocations and inversions which are fully viable this cannot be due to the elimination of spermatogonia with cell lethals, though such an explanation could apply to dominant lethals. Either the primary incidence of chromosome breakages in spermatogonia is low, or, with a normal incidence of breakages, rearrangements are inhibited, so that all breaks that fail to restitute lead to dominant lethals, which behave as cell lethals in spermatogonia.

Some rearrangements have been observed in Microtus spermatogonia by Ockey (1959) following TEM treatment but they were at a very low incidence and all those identified were confined to the sex chromosomes, which are a special case being overwhelmingly heterochromatic.

It follows that in comparisons of sensitivity patterns between rearrangements and mutations, differences for day I I can be taken for granted. It is the differences over days 2,5 and 8 which should receive our attention. Over this period, recessive lethals, both autosomal and sex-linked, and translocations show the same pattern. There is a sharp rise from day 2 (sperm) to day 5 (spermatids) followed by a fall on day 8 (spermatocyte or late spermatogonia?) to an intermediate sensitivity. Deleted X's are exceptional with a very different pattern. The rise from day 2 to day 5 is followed by a rise to day 8 which is proportionately the same but in absolute terms is much greater.

What is there special about deleted X's which separates them from the rest? It cannot be that they involve the sex chromosomes (c.f. sex-linked lethals), nor that they are structural changes (c.f. translocations). They have two distinct features, they are intra-changes and they are deletions.

In the Drosophila spermatocyte the nucleus is very large in comparison with the amount of chromatin it contains. The bivalents will be widely separated as can be confirmed cytologically in stages where the chromosomes are visible. This could explain why any rearrangements would tend to be intra-changes. Inversions have not been scored in this material. Deletions from the autosomes are lethal when large and when small are not readily detected. However, our data on induced crossing-over are valuable here. The excess of $r_{1}$ over $r_{2}$ was confined to days 6 and 7, that is to spermatocytes, and it has already been argued that this is probably due to small deletions. We therefore propose that deletions are a mutagenic response more readily induced in spermatocytes than elsewhere. The unique sensitivity pattern of

* Note added in proof. We have now verified that in spite of the shortage of sperm, the fertilisation rate on day 8 is normal: thus the high dominant lethal rate is genuine. 
deleted X's is therefore explained as follows. The variation in postmeiotic germ cells is governed by the general variation in sensitivity to mutagens affecting all kinds of mutational response. Spermatocytes, however, show a special propensity to induced deletions. Owing to the special condition of this type of cell, the most obvious hypothesis is that these deletions are produced by non-homologous crossing-over either between chromosomes or between sister chromatids.

There is one difficulty remaining. The peak incidence of deleted $\mathrm{X}$ 's is on day 8 , whereas the small deletions in our cross-over data were only detected on days 6 and 7. On day 8 however, there was an exceptionally high yield of true cross-overs $\left(r_{2}\right)$ which by error variation could mask the presence of small deletions $\left(r_{1}-r_{2}\right)$.

\section{SUMMARY}

$\mathrm{F}_{1}$ males irradiated with Iooor X-rays were mated on days 2, 5, 8 and I I after treatment to different classes of female. The incidence of dominant lethals, hyperploids and translocations (structural changes), and recessive autosomal and sex-linked lethals (gene changes) was measured for each day.

Estimates of induced crossing-over in the $b \mathrm{pr} v g$ region, made in daily samples from day 2 to day I3, were used to identify specific stages of germ cell development. In addition, the excess of animals showing a single recessive marker over those showing two markers was used to estimate the proportion of "mutations" or small deletions.

The pattern of sensitivity was similar for recessive autosomal and sex-linked lethals and translocations, showing a rise from day 2 (sperm) to day 5 (spermatids) followed by a fall on day 8 (spermatocytes or later spermatogonia?).

Deleted X's showed a unique sensitivity pattern with a peak on day 8. This was attributed to the high sensitivity of spermatocytes to intrachanges and in particular to deletions.

\section{REFERENCES}

ALEXANDER, M. L., AND STONE, W. s. 1955. Radiation damage in the developing germ cells of Drosophila virilis. Proc. Nat. Acad. Sci., 4 I , I046-57.

AUERBACH, C. 1954. Sensitivity of the Drosophila testis to the mutagenic action of X-rays. Z. indukt. Abstamm.-u. Vererb.-lehre., 86, I I3-25.

Bateman, A. J. I956. Mutagenic sensitivity of maturing Drosophila sperm. I. Dominant lethals. F. Genet., 54, 400-10.

bateman, A. J. 1957. Mutagenic sensitivity of maturing Drosophila sperm. II. Deleted X's. F. Genet., 55, 467-75.

FRIESEN, H. I937. Untersuchungen über Künstliche Auslösung von Crossing-Over in der Meiosis und Mitosis. (Russian with German summary). Biol. Zh., 6, I055.

Khishin, A. F. E. I955. The response of the immature testis of Drosophila to the mutagenic action of X-rays. Z. indukt. Abstamm.-u. Vererb.-lehre., 87, 97-I I 2.

LÜNING, K. G. I952a. X-ray induced dominant lethals in different stages of spermatogenesis in Drosophila. Hereditas, Lund., 38, $91-107$. 
LÜNYNG, K. G. 1952b. X-ray induced chromosome breaks in Drosophila melanogaster. Hereditas, Lund., 38, 32 I-38.

OAKBERG, E. F. 1955. Sensitivity and time of degeneration of spermatogenic cells irradiated in various stages of maturation in the mouse. Rad. Res., 2, 369-391. ockeY, C. H. 1959. Ph.D. Thesis. University of Manchester.

oster, I. I. 1955. Modification of X-ray mutagenesis in Drosophila. I. Reunion of chromosomes irradiated during spermiogenesis. Genetics, 4o, 692-6.

osTeR, I. I. I956. Modification of X-ray mutagenesis in Drosophila. II. Relative sensitivity of spermatids and mature spermatozoa. Advances in Radiobiol., 475-48o.

SOBELS, F. H., AND VAN STEENIS, H. 1957. Chemical induction of crossing-over in Drosophila males. Nature, I79, 29-3I.

STEVENS, W. L. 1942. Accuracy of mutation rates. 7. Genetics, 43, 301-307.

STONE, W. S., haAs, F., ALEXANDER, M. L., ANd Clayton, F. E. I954. Comments on the mechanism of action of radiations on living systems. Univ. Texas Publ. No. 5422, 244-27 I.

WARD, C. L., AND ALEXANDER, M. L. 1957. Cytological analysis of X-ray induced mutations at eight specific loci in the third chromosome of Drosophila melanogaster. Genetics, 42, 42-54. 